\title{
Analytical inventory of process variables for sustainable development of a small business for integrated production of wood pellets
}

\author{
Vasile Merticaru, ${ }^{1, *}$, Bogdan Rusu², and Romeo-Mihai Ciobanu ${ }^{2}$ \\ ${ }^{1}$ Gheorghe Asachi, Technical University of Iasi, Department of Machine Manufacturing Technology, \\ Prof. D. Mangeron Street, no. 39A, Iasi, Romania \\ ${ }^{2}$ Gheorghe Asachi, Technical University of Iasi, Department of Engineering and Management, Prof. \\ D. Mangeron Street, no. 28, Iasi, Romania
}

\begin{abstract}
The paper presents some theoretical considerations and the related deliverable results obtained within a research approach developed for analytically inventorying the process variables for a wood pellets micro-production activity integrated with self-providing crops of energetic willow. The study is part of a larger research approach intended to accurately define the appropriate specifications for developing a sustainable small business in this area. Within the particular research approach being discussed in the paper, some conceptual models have been structured and are proposed, based on process systematic analysis, as following: a model of the research general hypotheses; a model of the general conceptual research frame; a process flow model for the considered integrated processes, respectively wood pellets micro-production and energetic willow crops; a model for sustainability groups of indicators to be considered; two models for process variables inventorying and classification, one for each of the two considered integrated processes. After the research hypotheses are simplified by considering some particular implementing conditions, a final model of the investigated variables is submitted to discussion. Some adequate conclusions revealed by the research approach, together with some directions of further research development are finally identified and presented in the paper.
\end{abstract}

\section{Introduction. Research problem identification}

Within the actual global context, the problem of renewable energy resources is of vital interest. Biomass pellets and more specifically wood pellets gain more and more importance in this direction, as long as published statistical data show that in EU the consumption of pellets have increased from 3.8 mill. tons in 2005 to 9.8 mill. tons in 2010 and is expected to reach about 24 mil. tons in 2020, where about a half of it is imported, [1].

Among the biomass solutions for pellets production, energetic willow (Salix viminalis) outstands as a very performant wood type resource, if considering and balancing the

\footnotetext{
*Corresponding author: merticaru@tcm.tuiasi.ro
} 
positive and the negative arguments, [2]. More than that, looking from a holistic point of view, willow crops systems and the associated value chains can be considered as having a multifunctional role, as along with producing sustainable energy they bring other valueadded benefits to the related ecosystems and communities, [3].

In the particular situation of countries like Romania or even for more specific particularly delimited locations where a severe forest depletion by intensive wood mass exploiting is registered and where the local communities are highly dependent on the wood mass as heating energy resource, the sustainable development of some small businesses for integrating wood pellets micro-production and energetic willow crops appears as a viable solution. In order to provide sustainability for such projects the problem that arises is to identify the success/failure factors, to hierarchize and quantify them through a set of technical and economical specifications which the business process should be organized on.

Further on, the paper presents some theoretical considerations and the related deliverable results obtained within a research approach developed for analytically inventorying the process variables for a wood pellets micro-production activity integrated with self-providing crops of energetic willow. The study is part of a larger research approach intended to accurately define the appropriate specifications for developing a sustainable small business in this area.

\section{General conceptual research frame}

Within the above mentioned research approach, the conceptual frame and the related theories and principles have been clarified and first of all the research general hypothesis have been defined through a set of relations of association and of dependence and/or determination, as it is shown in the model presented in Figure 1.

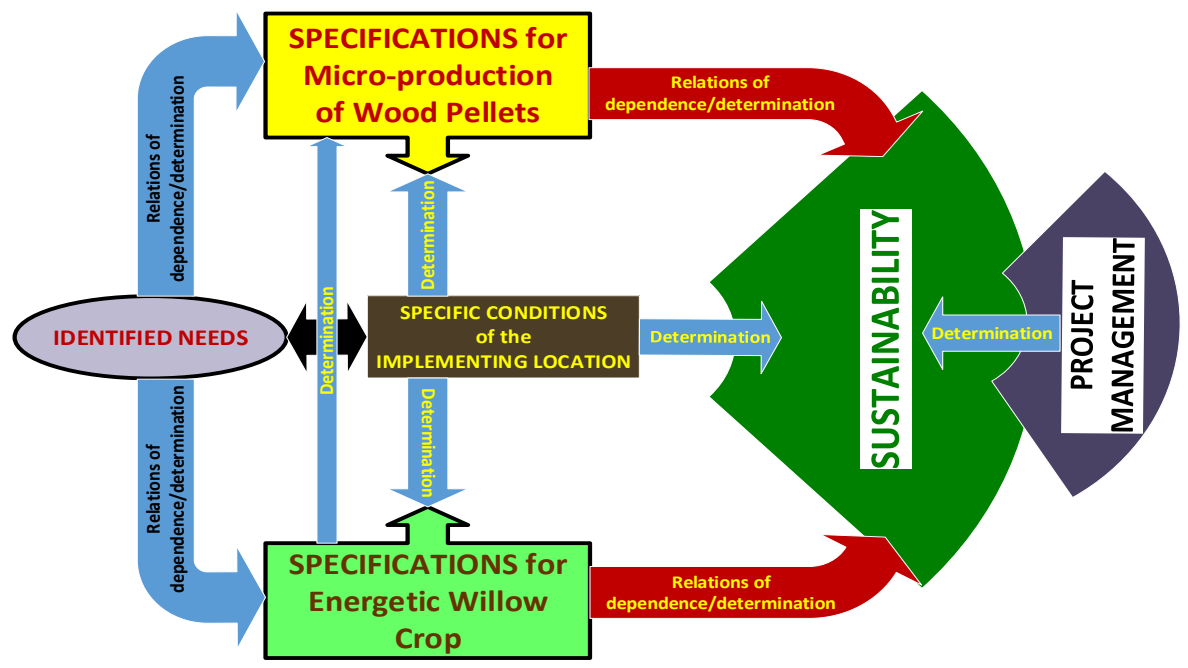

Fig. 1. Conceptual model of the research general hypotheses.

The particular needs targeted by the research project intention have been investigated and defined and the research general hypotheses have been further on customized and simplified by strictly reporting to the factors deriving from the specific conditions of the considered implementing location and to the particularities identified for the energetic willow cropping and for the wood pellets production processes, considered to be integrated. A model of the general conceptual research frame resulted from that phase, as in Figure 2. 


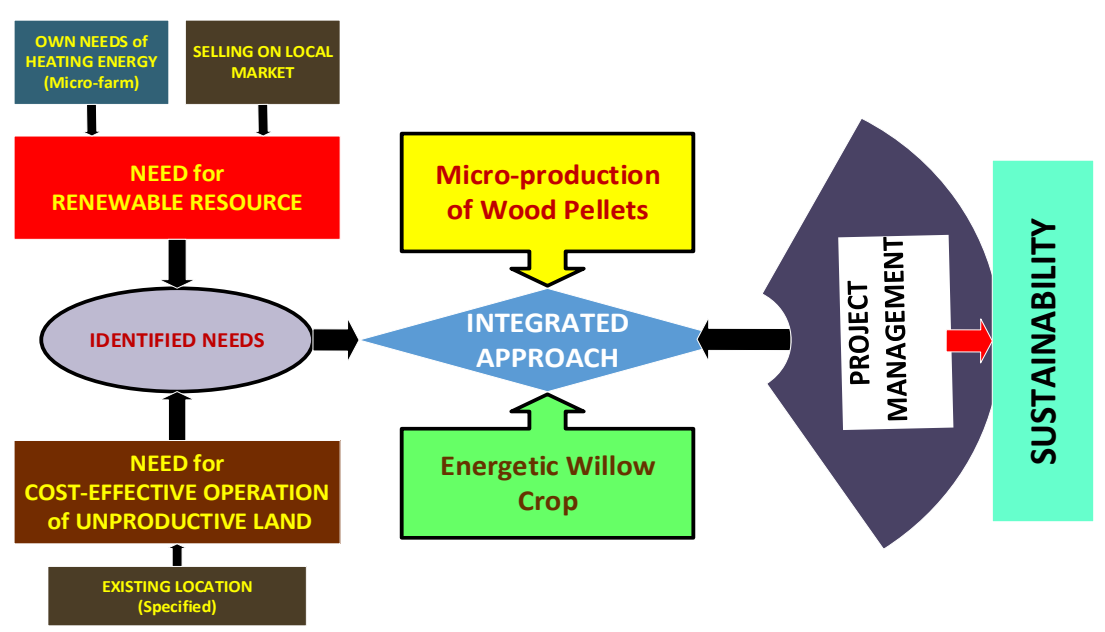

Fig. 2. Model of the general conceptual research frame.

\section{Systematic analysis of the integrated processes}

For analytically inventorying the process variables for providing the sustainable development of the particular process or project subjected to research study, a process systematic analysis has been carried out, starting with the functional and structural analysis of the two considered integrated processes, respectively wood pellets micro-production and energetic willow crops, in relation to the particularly targeted needs of renewable resources, respectively to satisfy some own needs of heating energy for a micro-farm and to be able to respond to the opportunity of selling wood pellets on local market, together with that of cost-effective operation of an existing unproductive land in specified location.

A comprehensive process workflow model has been targeted to be obtained as deliverable result, as it is shown in Figure 3. The functional and structural analysis of the energetic willow crop process have considered the technical recommendations of SUNYESF, [3], while that for the wood pellets micro-production process have considered technical data published by Piraglia et al., [4]. Not at last, some specific system/process/function decomposition rules have been considered in developing the right above mentioned process model.

Further on, a simple model as it is shown in Figure 4, has been elaborated for sustainability groups of indicators to be considered within the enlarged research approach, based on the state-of-the-art study and information related to LCSA - Life Cycle Sustainability Assessment, published by Kloepffer, [5]. All the three components of the Sustainable Development, respectively the ecological, economic and social impacts have been considered through some specific categories of indicators.

The detailed systematic analysis of the considered integrated processes have allowed the identification and classification of a large number of involved factors, which further on have been organized as process variables within two fishbone diagram models, one for each of the two investigated business processes, as it is shown in Figure 5.

As long as practically is very difficult to consider all the identified process variables in defining some relations of association and of dependence and/or determination between the input set of technical and economical specifications and the output set of qualitative and quantitative sustainability indicators, some further simplifying hypotheses have been considered, in relation to the particular implementing location and to the identified needs. 


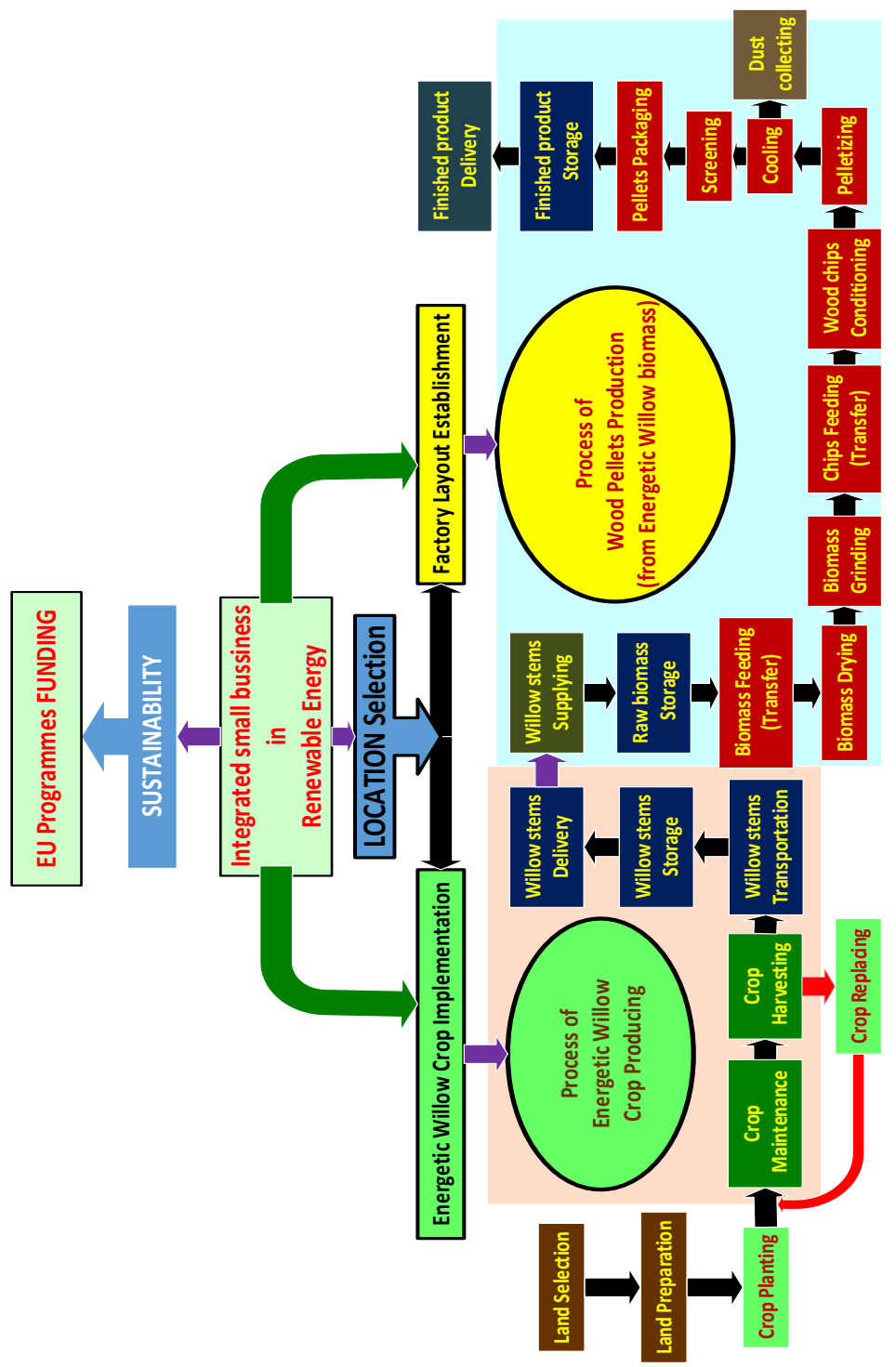

Fig. 3. Process flow model for the considered integrated processes.

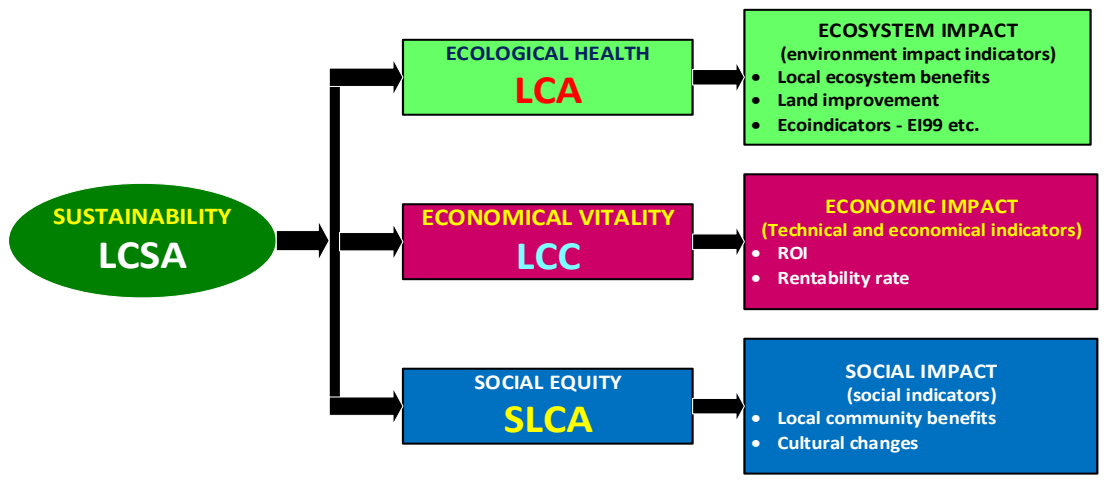

Fig. 4. Model for sustainability groups of indicators to be considered. 


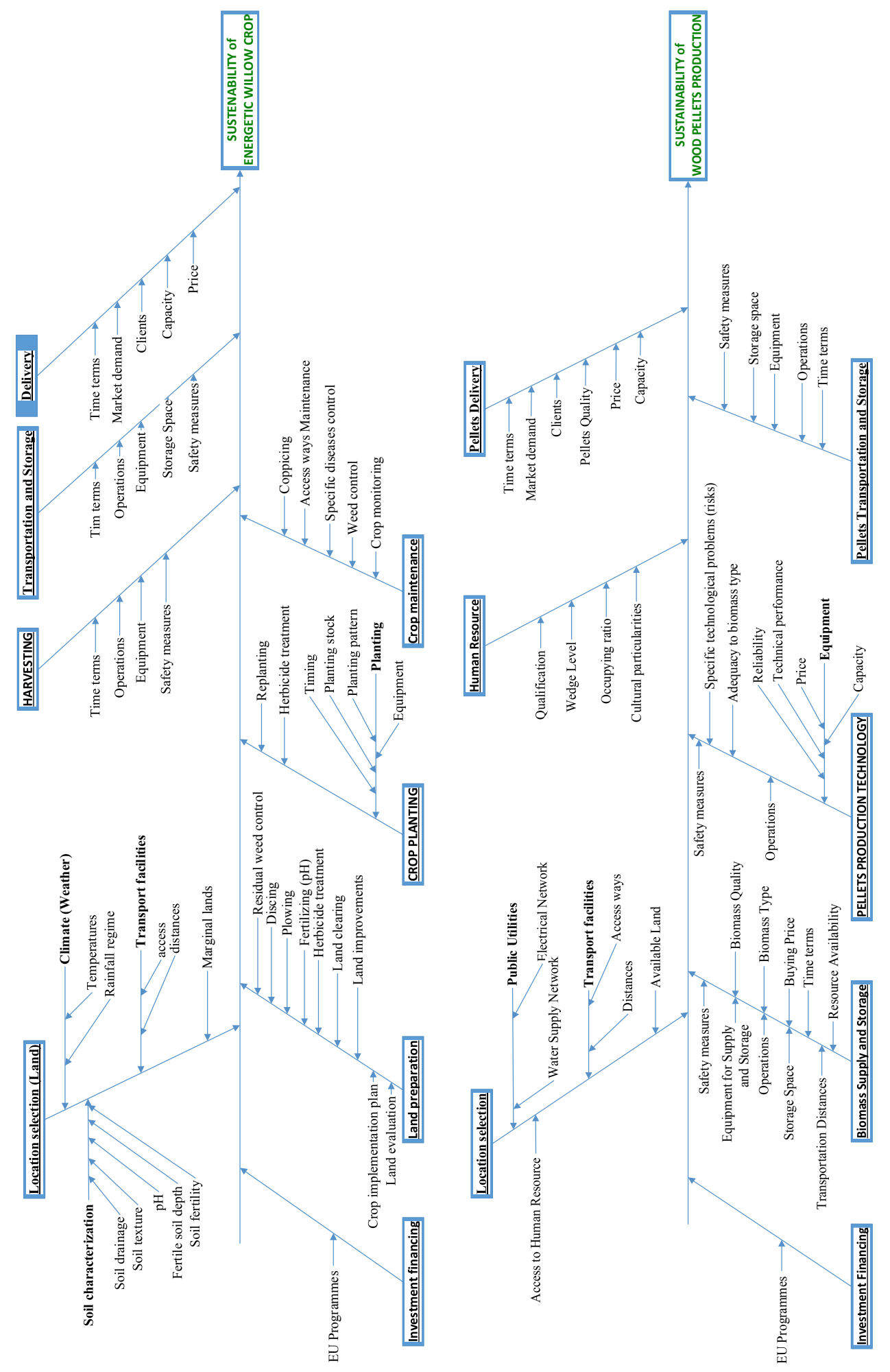

Fig. 5. Models for process variables inventorying and classification. 


\section{Selection of key process variables}

After the research hypotheses have been simplified by considering the set of the particular implementing conditions, a final model of the investigated variables has been elaborated as presented in Figure 6.

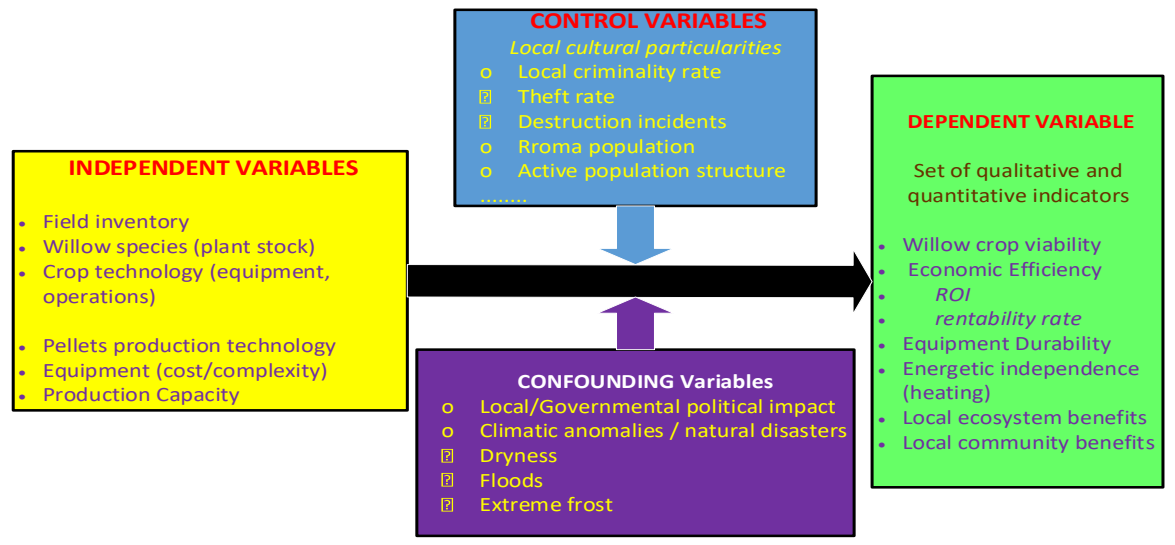

Fig. 6. Model of the research investigated variables.

\section{Conclusions}

In relation to the above presented considerations and models, there can be concluded that process systematic analysis based on process workflows models, on functional requirements analysis and, not at last, on system/process/function decomposition rules, can be an effective approach in analytically inventorying process variables for the sustainable development of a particular process or project.

As another conclusion of the above presented approach, some directions of further research development can be finally identified and presented here. First of all, there can be considered as useful and of interest to investigate the adapting of Axiomatic Design principles and tools, [6], in analytically inventorying, classifying and selecting the process variables to be considered in translating process requirements into process specifications for providing sustainability of a project or of a small business as in the discussed case study. Of real interest seem to be to further investigate the appropriateness of involving some Lean tools, [7], as well as some simple Excel-based inventory models, to identify the key process input variables.

\section{References}

1. C. Verhoest, Y. Ryckmans, Industrial Wood Pellets Report PellCert (2012)

2. A. Olejniczak, A. Cyganiuk, A. Kucińska, J.P. Łukaszewicz, Energetic Willow (Salix viminalis) - Unconventional Applications, Chapt. 9 in Sustainable Growth and Applications in Renewable Energy Sources, Ed. M. Nayeripour (2011)

3. SUNY-ESF, Willow Biomass Producers Handbook, (2017)

4. A. Piraglia, R. Gonzalez, D. Saloni, BioResources 5(4), 2374 (2010)

5. W. Kloepffer, Int J LCA 13(2), 89 (2008)

6. N.P. Suh, Axiomatic Design: Advances and Applications, Oxford University Press, New York, (2001)

7. J.W. Martin, Lean Six Sigma to Reduce Excess and Obsolete Inventory, iSixSigma (2010) 